\title{
What is a Good Job? Current Perspectives on Work and Improved Health and Well-Being
}

\author{
Emma J.K. Wadsworth, Katherine S. Chaplin, Paul H. Allen and Andrew P. Smith* \\ Centre for Occupational \& Health Psychology, Cardiff University, 63 Park Place, Cardiff, CF10 3AS, UK
}

\begin{abstract}
There is an extensive literature on the scale of, and risk factors for, stress at work, and outcomes associated with negative job characteristics and perceived stress. More recently, however, there has been a growing awareness that unemployment is harmful to health, and that work is beneficial and may be an effective way to improve health and wellbeing. However, there has been little attempt to draw together findings from this newer area. This paper gives an overview of current perspectives on work and its associations with improved health and well-being. It provides a framework for discussing the main themes which have emerged in this area. This framework allows consideration of the issues of conceptualisation, definition, approach and measurement which are important for future research. It is concluded that this area is still in its infancy, but clearly has the potential to make as influential a contribution as its negative counter-part. Currently, however, our understanding of what makes a good job and how we should conceptualise, study, and help workplaces provide that, is incomplete.
\end{abstract}

Keywords: Happiness, positive, satisfaction, work, workplace.

\section{INTRODUCTION}

In the last two to three decades there has been a large body of research on work characteristics and their association with both negative job outcomes, such as stress and dissatisfaction, and with physical and mental health [1-3]. Indeed, Cooper [9] concludes that the global recession is likely to lead to even more examples of stress-related illnesses and adverse occupational health outcomes. However, there has also been a growing awareness and acknowledgement that unemployment is harmful to physical and mental health, and that work is beneficial and may be an effective way to improve health and well-being [4]. There is also a large literature describing the well-established associations between negative psychological states and psychosocial factors, and mortality and health outcomes [5,6] much of it carried out in an occupational setting [7]. More recently, however, research has focused on the association between positive psychological states, such as positive affect and happiness, and health [8] though relatively little has been carried out in an occupational setting and/or using occupational outcomes.

Cooper [9] has argued that the bringing together of research on the negative effects of stress with the positive psychology of well-being [10] will improve the emotional capital and well-being of people in society. He states that we must understand what enhances as well as what depletes our mental capital [11]. There has been considerable discussion at a policy level on the association between good work and good health (e.g. the Black report on "Working for a Healthier Tomorrow"). A focus on good work can also be linked with positive organisational behaviours and also positive

*Address correspondence to this author at the Centre for Occupational \& Health Psychology, Cardiff University, 63 Park Place, Cardiff, CF10 3AS, UK; Tel: +44 292087 4757; Fax: +44 292087 4758;

E-mail: smithap@cardiff.ac.uk organisational scholarship, which looks at the ways in which employees and organisations flourish.

A recent meta-analytic review concluded that the psychosocial work environment is important for mental health [12]. In addition, longitudinal research has shown that work stressors are an important source of preventable psychiatric diagnoses in mid-life [13]. The relatively new focus on positive aspects of work considers whether the consistent evidence that particular (combinations of) negative job characteristics are prospective risk factors for common mental disorders [12] is mirrored by a positive impact of positive job characteristics.

Beddington et al. [14] have reviewed the Foresight Project on Mental Capital and Well-being. Mental capital encompasses cognitive and emotional resources and is a key dimension that predicts how an individual contributes to society and experiences a high quality of life. In contrast, mental well-being refers to the persons' ability to develop their potential, work productively and creatively and to have positive relationships with others. The two concepts are intimately linked which, in part, has caused problems in defining well-being. Indeed, the terms well-being, quality of life, life satisfaction and welfare are often used interchangeably. However, it is frequently suggested that well-being is a positive physical, social and mental state and not just an absence of pain, discomfort and incapacity [15]. Despite the frequent distinction between the presence of positive factors and the absence of negative ones, there is a tendency to still infer one from the other. For example, Wadell and Burton [4] clearly demonstrate that the absence of work is bad but do not provide much evidence about the positive aspects of different types of work. Similarly, Constable et al. [16] suggest that there is a general consensus about the characteristics which define "Good Jobs" and then sight factors largely based on the stress literature (e.g. demands, discretion and support; effort/reward imbalance). Pickvance [17] argues that to 
achieve well-being at work the same aspects of work that characterise "good work" have to be addressed. This, again, shows that it is important to address the question of what is a good job, and to do this by examining the work-well-being process. Studies of stress at work have shown that it is important to consider job characteristics, perceptions of stress, coping, and health outcomes (see [18] for a review of this approach). It is argued here that a similar approach can be used to give an overview of current perspectives on work and its associations with improved health and well-being. Following a review of the literature [19] it was felt that three main themes emerged from this material, and the different views on these issues are described below. This is, therefore, not an exhaustive account of the area but an initial integration of research that can form the basis for further research. Similarly, it does not attempt to review the measuring instruments used in the specific studies nor other features such as design and analysis.

\section{REVIEW}

The first topic considers research that has aimed to identify positive job characteristics.

\section{i. What Makes a "Good/Healthy" Workplace / Job?}

Much of the research on this topic tries to identify key elements that must be in place within an organisation to foster a wellness at work culture. Hillier et al. [20] suggest that these include conducive, welcoming and supportive environments that enable staff to form social networks, and more importantly the creation of trusting relationships and a sense of control over one's own working practices. They conclude that a job should be much more than simply a way of earning a living. It provides identity, contact and friendship with other people, a way of putting structure in your life and an opportunity to meet goals and contribute. Grawitch et al. [21] identify five general categories of healthy workplace practices: work-life balance, employee growth and development, health and safety, recognition, and employee involvement, using the Sauter et al. [22] definition of a healthy workplace as any organisation that "maximises the integration of worker goals for well-being and company objectives for profitability and productivity".

Warr [23, 24] suggests a list of 12 key characteristics of any job: Opportunity for personal control; Opportunity for skill use; Externally generated goals; Variety; Environmental clarity; Contact with others; Availability of money; Physical security; Valued social position; Supportive supervision; Career outlook; Equity. Other researchers have proposed a similar multi-factorial approach, although there is often an emphasis on the absence of negative influences. For example, Hillier et al. [20] suggest that factors that affect wellness in the workplace are many and include, for example, poor working environment (air quality, noise, crowding, lack of personal space), organisational culture and bullying. A problem with much of the research on work/job characteristics is that it is unclear whether it is the presence of positive characteristics (absence of negative characteristics) that is good, or whether it is the absence of positive characteristics (presence of negative characteristics) that is bad.

A related strand of work is that which starts from the standpoint of how a job can be improved [20] which is a literature review of ways of improving wellness at work with the aim of improving health, absenteeism and performance. This body of work seems to implicitly assume that removing (or the absence of) negative factors is the same as the presence of positive factors. Warr [23, 24] is an exception to this in suggesting that "it may be that an absence of the primary environmental characteristics leads to unhappiness, but that their presence beyond a certain level does not further increase happiness" [23]. In contrast other research starts from the premise that an aspect of "goodness" (such as job satisfaction) can be measured and that some people's jobs have more of it than others. This seems to assume that some characteristics of work are associated with "goodness" - though again this can mean the absence of negative factors and/or the presence of positive factors.

Research also suggests that the link between potentially beneficial workplace practices and employee and organisational outcomes is contingent on the effectiveness of the communication within the organisation and the alignment of the practices with the organisational context. Results suggest a direct pathway from healthy workplace practices to organisational improvements and also an indirect pathway from healthy workplace practices to organisational improvements through employee well-being [21]. Other analyses have shown that the relationship between working conditions and life satisfaction is strongly mediated by job satisfaction. Working conditions influence job satisfaction, which in turn influences life satisfaction [25]. However, job satisfaction is a complex concept and while it is assumed that having a good job leads to job satisfaction, this is not necessarily the case. People can be satisfied with their jobs because they have views other than those merely related to the content of the work itself. Various external components can also compensate for the lack of job quality [25]. Perhaps not surprisingly, organisational improvements receive more attention than employee well-being. There is some evidence that there is a bi-directional relationship between them; organisational improvements may lead to a better working environment. In addition, a happier workforce may work more efficiently and thus improve the performance of the organisation.

The question "What makes a good job?" covers a number of different areas, including the conceptualisation of the topic. Indeed, the answer to the question "What makes a good job" depends very much on the context (cultural, physical, political, geographical, social, and economic) in which it is asked. Similarly, this question can be interpreted in several ways. For example, it may consider what is perceived from the outside as a good job - perhaps one with a good salary and good career prospects. Alternatively, it may reflect the individual's perceptions of what, in their current situation, is a good job - perhaps one which suits childcare arrangements. Indeed, others [26] suggest that the focus should be on the dyad rather than the individual. It has also been observed that the same work characteristics can have different effects depending on the context and a range of other factors, so the question should, perhaps, be: "under what circumstances does work become beneficial?"

There are usually implicit assumptions that a good job is associated with a variety of health and safety outcomes. Again, the outcomes often reflect the absence of negative states rather than the presence of positive states (see next 
section). Indeed, some suggest that the impact of work extends to many other aspects of life. Researchers have found that a good job is an important predictor of life satisfaction in most EU countries [27-29] all referred to in [25]. In contrast, others find that no single aspect of the job is important in itself - rather it is the presence or absence of a job that is crucial since unemployment adversely affects life satisfaction [29-31]. Other research has examined associations between job satisfaction and life satisfaction, and results suggest that neither socio-demographic variables nor those for employment setting (such as occupation, working hours, type of contract) affect subjective life satisfaction to any great extent. Among the most influential predictors of life satisfaction are job security and intrinsic and extrinsic reward [25]. Job satisfaction in particular has been found to be related to a number of different outcomes which occur outside the work environment. Job characteristics and work culture can positively or negatively affect work-life balance and overall life satisfaction as well as well-being and health. Other research shows that, as well as acknowledging the human benefit of addressing employee wellness, it is important to consider effects on work performance. Much of the evidence reflects performance impairments in those workers who become "disengaged".

\section{ii. Positive Perceptions and Outcome Measures}

The second main theme to be considered is the measurement of positive perceptions and outcomes: well-being, job satisfaction, quality of life and so on. Well-being has usually been derived from two general perspectives: the hedonic approach which focuses on happiness and defines well-being in terms of pleasure attainment and pain avoidance; and the eudemonic approach which focuses on meaning and selfrealisation and defines well-being in terms of the degree to which a person is fully functioning [20]. However, other approaches use the term well-being to cover wide ranging outcomes (e.g. general physical health, general mental health, job satisfaction, employee morale, stress, motivation, organisational commitment and climate - [21] work related stress score, happiness, physical energy level, disability and pessimism level about personal health - [32]).

Warr [23] makes the distinction between 2 types of happiness:

1. Well being. (p.19): Relates to feelings, pleasure and excitement.

2. Self validation: '...happiness should not only be viewed in terms of pleasure. It also involves worthwhile activities or a realisation of the self, somehow meeting a standard of fittingness in relation to what one should be' (p.38).

He also discusses the relationship between happiness and unhappiness, starting with the suggestion that 'unhappiness is essential to happiness: in many settings people can only experience happiness in the presence of its converse; one is dependent on the other. In a similar manner, it may be that an absence of the primary environmental characteristics leads to unhappiness, but that their presence beyond a certain level does not further increase happiness.' (p.95). Most people have to struggle through difficult activities of some kind to meet their needs and sustain happiness. This has two implications for work. Firstly, there is a need to obtain a better understanding of the sources and nature of ambivalence. Secondly it is unrealistic to divorce experiences of happiness from task-orientated activities in a role. Rather than restricting attention to either happiness or performance on its own, the two should be studied simultaneously.

A wide range of factors have been considered when measuring well-being at work (e.g. relationships with colleagues and line managers; working environment and nature of the tasks carried out; supportive policies, such as health policies, at work etc). Well-being and job satisfaction (see below) often overlap, with job satisfaction being used as a measure of a good job and employee well-being. Differences between the studies in the use of terms, and the measurement of them, often make it impossible to make any realistic comparisons and draw any firm conclusions. Distinctions also need to be made between mental health, well-being and happiness and it is often unclear whether these are used as outcomes or mediating factors. Similarly, the relationship between well-being at work and general well-being need to be examined.

Job satisfaction is often described as a key concept relating to well-being at work. Rose [32] reviews evidence showing that job satisfaction is related to turnover [33, 34] absenteeism and lateness [35, 36], trade union involvement [37] , individual levels of stress [38], satisfaction with life in general [39] and longevity [40], as well as with gender [41, 42], general employee well-being [43] and employee commitment [44].

Job satisfaction has been measured in a number of different ways. In some studies [45] job satisfaction was measured using a single item. In contrast, others suggest that composite measures, including for example reward, job security, working conditions and so on, are more meaningful [32]. Others argue that many dimensions need to be assessed. For example, Krueger et al. [45] found 12 factors were associated with job satisfaction. Job satisfaction has also been found to be strongly associated with reward. Overall, people who perceive their work as being both intrinsically and extrinsically rewarding have higher levels of job satisfaction than those who do not. In a study by Wallace et al. [25], intrinsic rewards positively influenced job satisfaction in Western Europe to a greater extent than extrinsic rewards. In their model having an interesting job, financial rewards and career opportunities were associated with people feeling more satisfied with their work. The strongest influence was having an interesting job (coefficient of .29). The analyses conclude that quality of work, whether in the form of employment setting or perceived working conditions, plays a significant role in determining levels of job satisfaction. Generally, perceptions of working conditions are the most influential. Other research uses other measures as proxy measures of reward. For example, several studies use intention to turnover as a measure of job dissatisfaction without really investigating reasons for this intention (which may be, for example, career progression rather than dissatisfaction). In addition, while there are some commonalities, some predictors of job satisfaction seem to be organisation and context-specific [45].

Rose [32] also suggests that job satisfaction should cover extrinsic factors such as employment contract, skill and finance as opposed to work satisfaction which is related to 
intrinsic factors such as employee involvement, empowerment and self-actualisation. Rose [32] found that job satisfaction appears to be influenced by 5 different factors: (1) the terms and conditions of the employment contract; (2) hours of work; (3) money rewards; (4) the work situation; and (5) employees' work orientations and career aims. There was little evidence that variables bearing on the sociopsychological environment of a job exert the primary influence on job satisfaction scores. It was also argued that job satisfaction is complex, usually measured by satisfaction with a range of aspects of the job - such as satisfaction with rewards or working hours.

Similarly, research suggests that quality of working life is a multi-dimensional concept. When considering quality of working life one needs to consider features such as policies and procedures, leadership style, operations, and other general contextual factors of the setting. Research needs to consider a range of job characteristics and staff perceptions [45]. Studies investigating quality of working life have used a variety of different measures. For example, Wallace et al. [25] used 3 dimensions: working conditions, overall satisfaction with work, and perceptions of work-life balance. Other research (e.g. Edimansyah et al. [46]) has used the World Health Organisation Quality of Life questionnaire (brief version) which has four dimensions: physical health (e.g. pain, energy, sleep, mobility), psychological well-being (e.g. positive feelings, self-esteem, body image), social relationships (e.g. personal relations, sex, social support) and the environment (e.g. physical safety, transport, home environment, access to health and social care). These measures of quality of working life often include both risk factors that might lead to impairments and also outcome measures. The variation in measures across studies makes it difficult to provide an integrated overview of the area. The implicit assumption is often that profitable productive workplaces are those in which attention is given to the quality of life of employees while they are at work [20]. Evaluations of this are, however, generally lacking, as is the specific form that such changes might take.

\section{iii. Philosophical Background or Grounding}

Lastly, the literature in this area does not, generally, seem to have an acknowledged philosophical background, grounding or standpoint (c.f. the extensive literature on models or theories of stress). However, this is often implicit in what is written (e.g. any work is better than none; or quality of work, in particular perception of working conditions, is significant in determining level of job satisfaction). One exception that examines such issues within a clear framework is the approach of Warr $[23,24]$ to happiness at work. The main features of his approach are outlined below.

First, Warr [23] deconstructs a number of key concepts to make them more meaningful and measurable. A key contribution is Warr's 'Vitamin analogy' which likens positive work environment features to vitamins - increased vitamin intake is beneficial, but at a certain point greater intake will make no further difference. Warr [24], in a summary of his book, argues that the nature, sources and consequences of worker happiness are becoming defined [47, 48]. He outlines several issues which need to be considered when examining the topic and designing future research, including: considering multiple aspects of happiness; examining a wide range of environmental sources; looking for non-linear patterns as some desirable environmental sources become undesirable at high levels; considering job characteristics in combination and considering the possibility that they may be interactive and not just additive; exploring mental processes (for example in terms of the judgements made when appraising a situation) as well as environmental features; recognising the importance of personal baselines as people are consistent in their behaviours and mental processes across times and settings; acknowledging that unhappiness is essential to happiness.

\section{DISCUSSION}

Many of the articles in this area identify key factors associated with a "good" job or workplace and/or present measures of (work-related) well-being. The emphasis of both these strands of work is often on the multi-factorial or multifaceted nature of both well-being and positive job characteristics. The overriding impression we got from this material is that, however "goodness" is measured, it is multi-factorial [45]. However, we also felt that much of the work actually focuses on specific issues and often ignores factors that may be crucial in the "big picture". For example, the fact that in Western Europe and the US at least most people have chosen the jobs they are in and that this is not necessarily the case elsewhere, is largely ignored. It is, of course, virtually impossible to measure everything that may be important, and most of the work acknowledges some of its own gaps. However, very little looks at the combined effects of different factors. This is a point discussed by Warr [23] in relation to job characteristics, suggesting that the combined effect of variables may be interactive and not just additive. Quite often single outcome measures, such as job satisfaction, quality of work life etc [21,45] which use and compare more than one measure have been used, and it is often not clear whether any one of these measures is more appropriate or meaningful than any other.

Although issues of reward do come up, the concept of work as essential to having enough resources to participate in (Western European) society at a basic level - e.g. access to decent housing etc (as opposed to social standing on the basis of "job title") is not really touched on [4]. This comes back to the issue of working per se as better than not working (and so here things like minimum wage and loss of benefits are important), and only once working and earning enough to participate in society, does one ask what makes one job "better" than another. Indeed, using Warr's [23] terminology, it is possible to suggest that a large part of the negative effects of unemployment reflect poor self-validation rather than low happiness.

Certain themes or characteristics associated with job satisfaction and/or well-being and/or quality of work life do come up more than once: good organisational-employee communication [21, 45, 49]; decision latitude / autonomy / control [23, 45, 49-51]; low stress [21, 32, 49]; working hours - particularly distribution and pattern [26, 32]; recognition / fairness [23, 45, 49]; and social support [23, 50]. None of the work looks at job characteristics and "goodness" from a "dose response" perspective, which would also address the issue of whether the absence of negative job characteristics is equivalent to the presence of positive one, 
though Warr [23] points to the necessity of adopting such an approach.

Many papers focus on one occupational group only, making generalisations difficult, but they are often supportive of general themes which emerge [50, 51]. Similarly, there is little attempt to examine these issues at different stages of a person's career - looking back at a career may give a different perspective than that produced by most of the published research which focuses on perceptions of the current job. There are a number of covariates which need to be considered in studies of this type: earnings, job demands, gender, job conditions, job flexibility, how good a fit work hours are with own / family needs, flexibility of work hours and reasons for working a given schedule. Most research focuses on the individual however most employees do not live alone, so perhaps the household or family should be the unit of analysis. In addition most only consider direct effects and ignore possible moderating / mediating effects [26].

Similarly, there are a number of factors which have been identified in the studies reviewed here (and in other studies) showing associations between demographics and individual differences and health outcomes. It is, therefore, crucial that any research tries to control for the effects of these variables or at least adjusts for their effects. The papers reviewed provided little evidence that appropriate adjustment of confounding effects had been carried out. Most of the literature in this area, for example, fails to include personality. Warr $[23,24]$ is an exception, as are Hochter and Kiewitz [52], who suggest that positive affectivity is associated with job satisfaction. In addition, factors seem to be considered in isolation without adjusting for other confounding job characteristics or individual factors that may bias perceptions (positive/negative affectivity).

The term 'satisfaction' relates to the term 'satisfactory' which implies that things are as good as they can be whilst not being entirely outstanding. If someone said that they were 'satisfied' after a meal it would imply that they were as full as they would like or expect to be. Job satisfaction might therefore be interpreted as having a job which is acceptable, but in the literature a more positive interpretation is normally implied. Where job satisfaction is used to imply happiness confusion can therefore arise. The term satisfaction in itself embodies a relational disposition between expectation and outcome. Job satisfaction is a complex concept and while it is assumed that having a good job leads to job satisfaction, this is not necessarily the case. People can be satisfied with their jobs because they have views other then those merely related to the content of the work itself. Various external components can also compensate for the lack of job quality [25]. Happiness is a simpler, single directional construct. One might not feel as if one is in a definite state of happiness at work, but at the same time the fact that one is earning a living might make one very satisfied. Considering these two terms as interchangeable therefore has the potential to cause a great deal of confusion. Where job satisfaction is used as an outcome variable the danger is that only half the picture is considered. The research reviewed is all focused on what people actually experience but this is never compared with what they expect to experience which ties into a wider social and cultural context. If people accept and expect their job to be hard work then they may be entirely satisfied in condi- tions which other workers would simply not accept. Without tackling the essential definition of 'job satisfaction' it is therefore perhaps unsurprising that most of the studies fail to develop this topic.

Other areas of research may also fail to reflect what actually occurs. For example, the title of Warr's [24] article 'Searching for happiness at work' may also be quite misleading. Do people search for happiness at work? Most likely not, particularly outside the white collar and/or vocational sectors. It is more probable that they search for a working situation which is as good as it can be when all things are considered. And it's the 'all things considered' which have been frequently overlooked in the papers we have reviewed. This area is still in its infancy. Relatively little of the work has a clear philosophical background or grounding, and much of it fails to consider the wide range of other potentially influential factors. In this respect at least, there are similarities with the also relatively new area of positive affect in which research, with the exception of some longitudinal studies [53-55] includes relatively little control for negative affect. This makes it impossible to tell whether associations between positive affect and morbidity and mortality are in fact simply reflections of the well-established associations between negative psychological states and psycho-social factors and illness. However, if positive affect is associated with health independently of negative affect, then this work would add explanatory power to our existing understanding of the relationships between psychological states and mental and physical well-being. Very recent research is beginning to address this area. Burgdorf and Panskepp [56] have shown distinct neurobiological substrates for positive and negative affect. And in addition, Steptoe et al. [57], hypothesising that positive affect is protective because it is part of a larger cluster of favourable psychosocial attributes, have considered associations between positive affect and a range of factors while controlling for negative affect, and vice versa. These findings also have implications for the study of positive aspects of work.

\section{CONCLUSIONS}

The current literature has identified many factors associated with a good job or workplace. However it is measured, goodness is clearly multi-factorial. Indeed, a major problem is that many studies examine specific factors rather than combinations. Many papers focus on one occupational group making generalisations difficult. In addition, there is often a lack of control of demographics and other key individual differences. Conceptual issues relating to satisfaction and happiness also require further clarification. Despite its current limitations, this area clearly has the potential to make as influential a contribution as its negative counter-part. At presently, however, our understanding of what makes a good job and how we should conceptualise, study, and help workplaces provide that, is incomplete.

\section{ACKNOWLEDGEMENTS}

The work described in this paper was supported by IOSH. We would also like to thank the members of our steering committee and both Jo Williams and Christine Noble. The views expressed here reflect those of the authors and should not be taken to represent the policy of the sponsors. 


\section{REFERENCES}

[1] Smith A, Johal SS, Wadsworth E, Davey Smith G, Peters T. The scale of occupational stress: The Bristol stress and health at work study. HSE Research Report 265. Sudbury UK 2000.

[2] Stansfeld SA, Fuhrer R, Shipley MJ, Marmot MG. Work characteristics predict psychiatric disorder: prospective results from the Whitehall II study. Occup Environ Med 1999; 56: 302-7.

[3] Stansfeld SA, Head J, Marmot MG. Work-related factors and ill Health: The Whitehall II study. HSE Research Report 266. Sudbury UK 2000.

[4] Waddell G, Burton, AK. Is work good for you health and wellbeing? The Stationery Office: Norwich 2006.

[5] Kuper H, Marmot M, Hemmingway H. Systematic review of prospective cohort studies of psychosocial factors in the aetiology and prognosis of coronary heart disease. In: Elliott P. Marmot M, Eds. Coronary heart disease epidemiology, $2^{\text {nd }}$ ed. Oxford: Oxford University Press 2005; pp. 363-413.

[6] Everson-Rose SA, Lewis TT. Psychosocial factors and cardiovascular diseases. Annu Rev Publ Health 2005; 26: 469-500.

[7] Chandola T, Brunner E, Marmot M. Chronic stress at work and the metabolic syndrome: prospective study. Br Med J 2006; 332: 52125.

[8] Pressman SD, Cohen S. Does positive affect influence health? Psychol Bull 2005; 131: 925-71.

[9] Cooper C. Stress and well-being. Stress and Health 209; 25: 207.

[10] Diener E. Subjective well-being. Psychol Bull 1984; 95: 542-575.

[11] Cooper C. Stress and the global recession. Stress Health 209; 25: 127.

[12] Stansfeld SA, Candy B. Psychosocial work environment and mental health - a meta-analytic review. Scand J Work, Env Hea 2006; 32: 443-62.

[13] Stansfeld SA, Clark C, Caldwell T, Rodgers B, Power C. Psychosocial work characteristics and anxiety and depressive disorders in midlife: the effects of prior psychological distress. Occup Environ Med 2008; 65:634-42.

[14] Beddington J, Cooper CL, Field J, et al. The mental wealth of nations. Nature 2008; 455: 1057-60.

[15] Allin P. Measuring societal well-being. Econom Labour Market Rev 2007; 1: 46-52.

[16] Constable S, Coats D, Bevan S, Mahdon M. Good Jobs. HSE Research Report 713. Sudbury UK 2009.

[17] Pickvance S. What is well-being at work? Occup Health [At Work] 2009; 6: 35-37.

[18] Mark GM, Smith AP. Stress models: a review and suggested new direction. In: Houdmont J, Leka S, Eds. Occupational Health Psychology: European Perspectives on research, education and practice. Vol. 3. EA-OHP series. Nottingham University Press 2008; pp. 111-144.

[19] Smith A, Wadsworth EJK, Chaplin K, Allen P, Mark GM. The relationship between work/working and improved health and wellbeing. IOSH report. Leicester UK 2010.

[20] Hillier D, Fewell F, Cann W, Shephard V. Wellness at work: Enhancing the quality of our working lives. Int Rev Psychiatr 2005; 17: 419-31.

[21] Grawitch MJ, Gottschalk M, Munz DC. The path to a healthy workplace: A critical review linking healthy workplace practices, employee well-being, and organizational improvements. Consult Psychol J 2006; 58: 129-47.

[22] Sauter SL, Lim S-Y, Murphy LR. Organizational health: a new paradigm for occupational stress research at NIOSH. Jpn J Occup Mental Health 1996; 4: 248-54.

[23] Warr PB. Work, happiness, and unhappiness. Mahwah, NJ: Erlbaum 2007.

[24] Warr PB. Searching for happiness at work. Psychologist 2007; 20: 726-9.

[25] Wallace C, Pichler F, Hayes BC. First European Quality of Life Survey: Quality of work and life satisfaction. European Foundation for the Improvement of Living and Working Conditions: Dublin 2007.

[26] Barnett RC. Relationship of the number and distribution of work hours to health and quality-of-Life (QOL) outcomes. Res Occup Stress Well Being 2006; pp. 99-138.

[27] Delhey J. European Foundation for the Improvement of Living and Working Conditions, Life satisfaction in an enlarged Europe, Luxembourg, Office for Official Publications of the European Com- munities 2004. Available from: http://www.eurofound.europa.eu/ publications/htmlfiles/ef03108.htm

Böhnke P, European Foundation for the Improvement of Living and Working Conditions, First European Quality of Life Survey: Life satisfaction, happiness and sense of belonging, Luxembourg, Office for Official Publications of the European Communities 2005. Available from: http://www.eurofound.europa.eu/publications/htmlfiles/ef0591.htm

[29] Haller M, Hadler M. How social relations and structures can produce happiness and unhappiness: An international comparative analysis. Soc Indicators Res 2006; 75: 169-216.

[30] Frey B, Stutzer A. Happiness research: State and prospects. Rev Soc Econ LX11 2005; 207-28.

[31] Kapitány B, Kovaks K, Krieger H. European Foundation for the Improvement of Living and Working Conditions, Working and living in an enlarged Europe, Luxembourg, Office for Official Publications of the European Communities 2005. Available from: http://www.eurofound.europa.eu/publications/htmlfiles/ef0595.htm

[32] Rose M. Good deal, bad deal? Job satisfaction in occupations. Work, Employ Soc 2003; 17: 503-30.

[33] Freeman RB. Job satisfaction as an economic variable. Am Econ Rev 1978; 93: 135-41.

[34] Freeman RB. The exit-voice tradeoff in the Labor Market: Unionism, Job Tenure, Quits, and Separations. Q J Econ 1980; 95: 64373 .

[35] Clegg CW. Psychology of employee lateness, absence and turnover: A methodological critique and empirical study. J Appl Psychol 1983; 68: 88-101.

[36] Mangione TW, Quinn RP. Job satisfaction, counterproductive behaviour and drug use at work. J App Psychol 1975; 60: 114-16.

[37] Borjas GJ. Job satisfaction, wages and unions. J Hum Resour 1979; 4: $21-40$.

[38] Jamal M. The job stress and job performance controversy: An empirical assessment. Organ Behav Human Performance 1984; 33 $1-21$

[39] Judge TA, Watanabe S. Another look at the job satisfaction-life satisfaction relationship. J App. Psychol 1993; 78: 939-48.

[40] Palmore E. Predicting longevity: a follow-up controlling for age. J Geron 1969; 39: 109-16.

[41] Clark AE. Job satisfaction and gender: Why are women so happy at work?. Labour Econom 1997; 4: 341-72.

[42] Sloane PJ, Williams H. Job satisfaction, comparison earnings, and gender. Labour 2000; 14: 473-501.

[43] Blanchflower D, Oswald A. Well-being over time in Britain and the USA, Working Paper 7487. Washington: National Bureau of Economic Research 2000.

[44] Frey BS. Not Just for the money. Cheltenham: Edward Elgar 1997.

[45] Krueger P, Brazil K, Lohfeld L, Edward HG, Lewis D, Tjam E. Organization specific predictors of job satisfaction: Findings from a Canadian multi-site quality of work life cross-sectional survey. BMC Health Serv Res 2002; 2: 1-8.

[46] Edimansyah BA, Rusli BN, Naing L, Rusli BAM, Winn T. Relationship of psychosocial: work factors and health-related quality of life in male automotive assembly workers in Malaysia. Ind Health 2007; 45: 437-48.

[47] Judge TA, Thoresen CJ, Bono JE, Patton GK. The job satisfactionjob performance relationship: A qualitative and quantitative review. Psychol Bull 2001; 127: 376-407.

[48] Kinicki AJ, McKee-Ryan FM, Schriesheim CA, Carson KP. Assessing the construct validity of the Job Descriptive Index: A review and meta-analysis. J Appl Psychol 2002; 87: 14-32.

[49] Blegen MA. Nurses' job satisfaction: a meta-analysis of related variables. Nurs Res 1993; 42: 36-41.

[50] Beasley JW, Karsh BT, Hagenauer ME, Marchand L, Sainfort F. Quality of work life of independent versus employed family physicians in Wisconsin: A WReN study. Ann Family Med 2005; 3: 500-506.

[51] Nasermoaddeli A, Sekine M, Hamanishi S, Kagamimori S. Associations between sense of coherence and psychological work characteristics with changes in quality of life in Japanese civil servants: A 1-year follow-up study. Ind Health 2003; 41: 236-41.

[52] Hochwarter WA, Kiewitz C. Positive affectivity and collective efficacy as moderators of the relationships between perceived politics and job satisfaction. J Appl Soc Psychol 2003; 33: 1009-35. 
[53] Blazer DG, Hybels CF. What symptoms of depression predict mortality in community-dwelling elders? J Am Geriatr Soc 2004; 52: 2052-56.

[54] Ostir GV, Markides KS, Black SA, Goodwin JS. Emotional wellbeing predicts subsequent functional independence and survival. J Am Geriatr Soc 2000; 48: 473-8.
[55] Ostir GV, Markides KS, Peek MK, Goodwin JS. The association between emotional well-being and the incidence of stroke in older adults. Psychosom Med 2001; 63: 210-5.

[56] Burgdorf J, Panksepp J. The neurobiology of positive emotions. Neurosci Biobehav R 2006; 30: 173-187.

[57] Steptoe A, O'Donnell K, Marmot M, Wardle J. Positive affect, psychological well-being and good sleep. J Psychosom Res 2008; 64: 409-5.

Received: February 08, 2010

(C) Wadsworth et al.; Licensee Bentham Open.

This is an open access article licensed under the terms of the Creative Commons Attribution Non-Commercial License (http://creativecommons.org/licenses/by-nc/3.0/) which permits unrestricted, non-commercial use, distribution and reproduction in any medium, provided the work is properly cited. 